\title{
Alberta Gastroenterologists Symposium: A debate of the proposal that patients with duodenal ulcer in 1992 should be treated with antibiotics
}

\author{
EOIN A LALOR, MB, NOEL B HERSHFIELD, MD, RICHARD N FEDORAK, MD
}

EA LALOR, NB HERSHFIELD, RN FEDORAK. Alberta Gastroenterologists Symposium: A debate of the proposal that patients with duodenal ulcer in 1992 should be treated with antibiotics. Can J Gastroenterol 1993;7(4):359-363. It has become clear that Helicobacter pylori is associated with duodenal ulcer disease and antral gastritis. Furthermore, it has been demonstrated that eradication of $\mathrm{H}$ pylori can, in some instances, reduce the incidence of duodenal ulcer relapse. Nevertheless, the most appropriate therapy, as well as its duration and frequency of administration, remain undetermined. Whether all patients with the organism, a subset or none should be treated remains a debatable question. This timely topic was debated by Dr Eoin A Lalor (protagonist) and Dr Noel Hershfield (antagonist) at the Alberta Gastroenterologists Symposium from November 1 to 3, 1991.

Key Words: Duodenal ulcer, Gastritis, Helicobacter pylori, Ulcer relapse

Symposium des gastro-entérologues albertains: débat sur l'antibiothérapie proposée chez des patients atteints d'ulcère duodénal en 1992

RÉSUMÉ: Il est devenu évident que Helicobacter pylori est associé avec la maladie ulcéreuse duodénale et la gastrite antrale. De plus, il a été démontré que l'éradication de $H$. pylori peut dans certains cas réduire la fréquence des récidives d'ulcère duodénal. Néanmoins, le traitement le plus approprié, sa durée et sa fréquence d'administration demeurent à préciser. Il reste encore à déterminer si l'on doit traiter tous les patients porteurs de ce pathogène, un sous-groupe seulement ou si l'on doit n'en traiter aucun. Ce sujet d'actualité a fait l'objet d'un débat entre le docteur Eoin A. Lalor (en faveur) et le docteur Noel B. Hershfield (contre), lors du symposium des gastro-entérologues albertains qui a eu lieu du $1^{\mathrm{er}}$ au 3 novembre 1991.

Departments of Medicine, Divisions of Gastroenterology, University of Alberta and University of Calgary, Alberta

Correspondence: Dr Eoin A Lalor, University of Alberta, Department of Medicine, Division of Gastroenterology, 2E1.01 Walter Mackenzie Health Sciences Centre, Edmonton, Alberta T6G 2R7. Telephone (403) 492-8148, Fax (403) 492-3340

Received for publication June 26, 1992. Accepted April 6, 1993 


\section{Proposed: EOIN A LALOR}

$\mathrm{T}$ HE JUSTIFICATION FOR TREATING PATIENTS WITH DUO. denal ulcers with antibiotics in 1992 include the main reasons for treating duodenal ulcer disease. These include the prevention of symptoms, complications and recurrence, as well as the potential reduction of surgery, and morbidity and mortality rates. There are no data at this time to show that the eradication of helicobacter with antibiotic therapy achieves any of these goals except for the prevention of recurrence, but further long term studies ought to show permanent healing and reduced recurrence of duodenal ulcers. Were long term eradication proved attainable through antibiotic therapy, a comparison of the costs of this type of therapy with long term maintenance therapy would likely show antibiotics to be the cost-effective treatment of choice.

Recent evidence has linked Helicobacter pylori infection with an increased risk of gastric carcinoma; however, this link remains potentially spurious. In particular, a plausible biological explanation for this association is lacking, and clearly the organism is neither sufficient to cause this disease nor is its presence necessary for the development of gastric carcinogenesis. Nevertheless, were the link proved to exist, antibiotic therapy would be a necessity.

$\mathrm{H}$ pylori is a Gram-negative curved bacillus found in the gastric antrum. Virtually $100 \%$ of the patients with chronic antral gastritis carry this bacillus, and it is found in 90 to $95 \%$ of patients who have duodenal ulcer disease. Drs Marshall and Warren of Perth, West Australia, identified the organism in 1983, although it had previously been observed in the early 1900 s when it was felt to be a contaminant. In 1975, it was again described, but culture yielded pseudomonas, presumably a contaminant. Therefore, the organism was not officially named until 1983 . Two human volunteer studies have taken place, one of which was short-lived. The other, which required multiple attempts at eradication and included a four-year follow-up, was reported by Dr A Morris and colleagues (1) in 1991.
The organism lives in the gastric mucus adjacent to the epithelial cell, produces an inflammatory reaction both acute and chronic, and presumably at sites of gastric metaplasia in the bulb, produces duodenal ulceration, biopsies of which will not show the organism and frequently will not even show gastric metaplasia (which has eroded away and is only present adjacent to the acute ulcer).

The helicobacter organism produces several defensive substances, including superoxide dismutase, urease and catalase. Considerably more research needs to be done on the offensive compounds helicobacter produces. It is known to produce a cytotoxin, a lipase which may break down cell membranes and a mucinase which aids in its movement through gastric mucus. It produces chemotactic substances and, as recently demonstrated by Negrini et al (2), induces the production of antibodies which cross-react with human gastric mucosa.

A hypothesis is required to explain how $\mathrm{H}$ pylori might cause a duodenal ulcer and why not all patients who harbour $H$ pylori get duodenal ulcers. Environmental factors are clearly involved in colonization. Genetic factors in both organism and host are probably involved, and it appears that some patients become hypochlorhydric initially and experience temporary parietal cell failure. Perhaps some of these patients become hypergastrinemic and, with recovery of parietal cell function, develop hyperacidity and gastric metaplasia of the duodenal bulb followed by colonization of the duodenal bulb and duodenal ulceration.

In considering treatment, meta-analysis by Chiba et al (3) shows single antibiotic therapy with either amoxicillin or bismuth produces an eradication rate of $18.6 \%$, therapy consisting of bismuth plus one antibiotic produces an eradication rate of 43.7 to $55.1 \%$ and triple therapy, usually bismuth with two antibiotics, gives an overall eradication rate of $82.3 \%$.

Several poorly controlled studies report (usually as 'Letters to the Editor') effective monotherapy of duodenal ulcers using antibiotics alone, specifically furazolidine and metronidazole (the former drug is not available in Canada).

As well, Goodwin in Perth proposes a leaking roof concept' where the 'rain' is acid secretion and helicobacter pro-

\section{TABLE 1}

\section{Helicobacter pylori controlled trials}

\begin{tabular}{|c|c|c|c|c|c|c|c|}
\hline \multirow[b]{2}{*}{ Author } & \multirow[b]{2}{*}{$\mathrm{RCT}$} & \multirow[b]{2}{*}{ Double-blind } & \multirow[b]{2}{*}{ Number } & \multirow[b]{2}{*}{ Prescription } & \multirow[b]{2}{*}{ Eradication rate } & \multicolumn{2}{|c|}{ Duodenal ulcer relapse rate/year } \\
\hline & & & & & & $\mathrm{Hp}+$ & $\mathrm{Hp}-$ \\
\hline \multirow[t]{2}{*}{ Coghian } & Yes & No & 66 & Cimetidine & $17 \%$ & \multirow{2}{*}{$79 \%$} & \multirow{2}{*}{$27 \%$} \\
\hline & & & & CBS & $52 \%$ & & \\
\hline \multirow[t]{3}{*}{ Marshall } & Yes & Yes & 100 & Cimetidine & $0 \%$ & \multirow{3}{*}{$84 \%$} & \multirow{3}{*}{$21 \%$} \\
\hline & & & & Cimetidine and tinidazole & $5 \%$ & & \\
\hline & & & & CBS and tinidazole & $70 \%$ & & \\
\hline \multirow[t]{2}{*}{ Rauws } & Yes & No & 50 & CBS & $8 \%$ & \multirow{2}{*}{$81 \%$} & \multirow{2}{*}{$0 \%$} \\
\hline & & & & CBS and met/tet & $79 \%$ & & \\
\hline
\end{tabular}

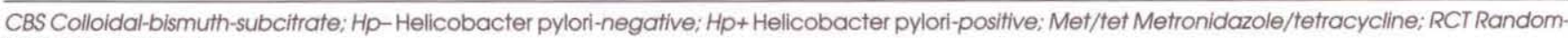
ized controlled trial 
duces a 'hole in the roof'. Goodwin asks, "why not repair the roof (with bismuth or something else) and then let it rain all it wants and there will be no leak".

Graham et al (5) reported that in a single-blind, randomized controlled trial, 105 patients were treated either with ranitidine $300 \mathrm{mg}$ daily or ranitidine plus 'triple therapy' (tetracycline, metronidazole and bismuth subsalicylate). They found a significant difference in healing rates at both two and four weeks; healing rates went from $53 \%$ with ranitidine to $74 \%$ with combination therapy. The poor healing rate in the ranitidine group was felt to be due to the fact that more severe ulcer cases tend to be seen in tertiary centres. Also, a number of patients continued to take nonsteroidal anti-inflammatory drugs (NSAIDs) throughout the study.

Table 1 shows the three major controlled trials undertaken to date $(6-8)$. These three trials are randomized (maintaining a double-blind trial is difficult because of the side effects of bismuth therapy); they show an eradication rate of 70 to $80 \%$, with a very significant endoscopically determined reduction of ulcer relapse over the following year, from the average figures of 80 to $84 \%$ seen after $\mathrm{H}_{2}$-blocker therapy to between 0 and $27 \%$ (for cases of confirmed eradication).

One of the main stumbling blocks to helicobacter eradication is the complex, potentially dangerous and poorly tolerated triple therapy regimen. However, major advances have been made in this area, and a large number of alternative regimens were described at the American Gastroenterological Association meetings in New Orleans in May 1991. Standard therapy has evolved to a regimen of bismuth, metronidazole and either tetracycline or amoxicillin. Some researchers wonder if bismuth subsalicylate might be less efficacious than bismuth subcitrate but Graham's study (5), previously described, used bismuth subsalicylate. As well, some authors believe the third antibiotic is not necessary, and newer regimens replace the bismuth completely, using omeprazole, ranitidine or even sulcralfate. Shorter courses have included four-day triple therapy which gives an eradication rate of 50 to $67 \%$, five-day triple therapy without bismuth and even a one-day (in-patient) therapy reported from Italy.

Borody et al (9) have estimated the economic impact of treating $H$ pylori with antibiotics. They suggest that triple therapy in the United States could result in a health care savings of over US $\$ 60$ billion over a 15-year interval. My assessment of the Canadian situation is based on a $2 \%$ prevalence of duodenal ulcer disease, with $10 \%$ of ulcers possibly requiring maintenance therapy. $\mathrm{H}_{2}$-blocker therapy at $\$ 120$ for two months of curative treatment and $\$ 30$ a month for the remainder of five years of maintenance adds up to $\$ 1,860$. In comparison, eradication therapy - which includes a month of $\mathrm{H}_{2}$-blocker therapy to render the patient well $-\$ 40$ worth of bismuth subsalicylate and the price of 10 to 14 days of antibiotics runs well under $\$ 200$. The difference to Canadian health-related spending is well in excess of $\$ 50$ million over five years, and this figure does not take into account the patients who would develop new ulcers during this time. The cost of endoscopy and investigation has not been included here but would ideally include an initial diagnostic endo- scopy, including a biopsy of the antrum and a follow-up biopsy done at least one month after the end of the eradication therapy to confirm the absence of the organism. Obviously, noninvasive tests, in particular the urea breath test, may allow for confirmation of eradication in future.

In summary, I think it is clear from the current evidence that combination antibiotic therapy should be prescribed for certain patients with duodenal ulcer disease. Patient compliance can be enhanced by obtaining informed consent and by explaining the natural history of duodenal ulcer disease. Triple therapy can include bismuth subsalicylate rather than bismuth subcitrate. The rate of reinfection after eradication is very low, and it may be inappropriate to wait for a gold standard trial which may never be published because the treatment consists predominantly of orphan drug therapy and funding for a large trial is unlikely to be forthcoming.

\section{REFFERENCES}

1. Morris AJ, Ali MR, Nicholson GI, Perez-Perez, GI, Blaser MJ. Long-term follow-up of voluntary ingestion of Helicobacter pylori. Ann Intern Med 1991;114:662-3.

2. Negrini R, Lisato L, Zanella I, et al. Helicobacter pylori infection induces antibodies cross-reacting with human gastric mucosa. Gastroenterology 1991;101:437-45.

3. Chiba N, Rao BV, Rademaker JW, Hunt RH. Meta-analysis of the efficacy of antibiotic therapy in eradicating Helicobacter pylori. Am J Gastroenterol 1992;87:1716-27.

4. Goodwin CS. Duodenal ulcer, Campylobacter pylori, and the 'leaking roof' concept. Lancet 1988;ii:1467-9.

5. Graham DY, Lew GW, Evans DG, Evans DJ Jr, Klein PD. Effect of triple therapy (antibiotics plus bismuth) on duodenal ulcer healing. A randomized controlled trial. Ann Intern Med 1991;115:266-9.

6. Rauws EA, Tytgat GN. Cure of duodenal ulcer associated with eradication of Helicobacter pylori. Lancet 1990;335:1233-5.

7. Marshall BJ, Goodwin CS, Warren JR, et al. Prospective double-blind trial of duodenal ulcer relapse after eradication of Campylobacter pylori. Lancet 1988;ii:1437-42.

8. Coghlan JG, Gilligan D, Humphries H, et al. Campylobacter pylori and recurrence of duodenal ulcers - a 12-month follow-up study. Lancet 1987;ii:1109-11.

9. Borody T, Andrews P, Ostapowicz N, George, L, Brandl S. Economic impact of duodenal ulcer cure using 'triple therapy' in the US. Gastroenterology 1991;100:A36.

\section{Against: NOEL HERSHFIELD}

\section{W} E KNOW THE FOLLOWING ABOUT THIS PARTICULAR organism now called helicobacter: it is relatively rare in children and increases in incidence as the population ages, reaching levels of about $50 \%$ at about age 50 years everywhere it has been studied. It appears to be very common in poorer regions and in the Far East; the population reports from Thailand, Malaysia and Hong Kong indicate that helicobacter lives in the stomachs of 70 to $80 \%$ of the adult population over age 50 years. Quite clearly, as has been explained to you, very few of these people ever develop any disease caused by helicobacter.

Helicobacter is present in all patients who have antral gastritis. I think that's fairly well established, and helicobacter 
certainly is considered to be the cause of antral gastritis whether that gastritis gives any symptoms at all. Antral gastritis is an asymptomatic condition and obviously doesn't need to be treated, although I have now seen a number of patients who have been endoscoped here and there and who are currently experiencing functional dyspepsia, having been treated with three antibiotics and bismuth. The bismuth available in Canada contains a good deal of acetylsalicylic acid (ASA), and I assume that some of the dyspepsia pain is masked by the ASA-containing bismuth. Helicobacter is present, according to most studies, in 90 to $100 \%$ of patients with duodenal ulcer. It is present in half the people who have gastric ulcers, and it's apparently now considered perhaps permissive in some patients who have ulcers of the stomach induced by nonsteroidals. It is also present in many people who have nonulcer dyspepsia and in various other cases. Interestingly enough, it is also present in the case of regenerating small intestinal Crohn's disease where there is incidence of gastric metaplasia. Helicobacter is very common and, except in the treatment of duodenal ulcer (and that's the only area where there is any controversy), most people are still in the dark as to what all this means.

This uncertainty brings us to our subject: should we treat the infection of the antrum - because that's what we're doing - and the metaplastic mucosa of the duodenum with antibiotics or should we continue to treat the condition as we always have, with some kind of antacid therapy, whether it be antacids in the classic sense, pump inhibitors or $\mathrm{H}_{2}$ inhibitors? Enthusiasts suggest that the treatment of choice is now bismuth plus one, two or three antibiotics, but a recent meta-analysis of, I think, 243 studies (which has been alluded to by my antagonist here) suggests that three antibiotics three antibiotics - is best (1).

Now that they can show that an ulcer heals in the same time that it does when treated with $\mathrm{H}_{2}$ inhibitors or omeprazole, and that it only recurs if the Helicobacter pylori infection recurs, the conclusion they have drawn is that if you eradicate the $H$ pylori, you will eradicate the ulcer forever. Forever being, as far as I'm aware, two years to date. It's a very compelling argument and I can't refute the world-wide evidence which shows that, if the infection is successfully treated, the ulcer disappears - I don't think anybody can do that.

I do have some concerns. At present, we have some very effective treatment regimens for duodenal ulcer. Are we now to abandon this effective treatment? And should we substitute a treatment consisting of two or maybe three drugs all of which may have significant side effects? These side effects have not been carefully documented in many of the articles I have read, and some of the side effects that have been mentioned include, of course, antibiotic sensitivity and pseudomembraneous colitis. Antibiotics aren't necessarily the treatment of choice.

In addition, we don't really know about the recurrence rate of $H$ pylori because the studies have been using biopsies to determine whether the organism has been eradicated. Some evidence now exists which suggests that if you eradicate $\mathrm{H}$ pylori in the antrum, it migrates up to the fundus. Some researchers even say that the organism is always present in the fundus and it is only when, for some unknown reason, the $\mathrm{H}$ pylori migrates down to the antrum that it causes gastritis.

The other thing that concerns me about antibiotic treatment is the fact that if $H$ pylori does recur, it may very well recur in a resistant form. Are we then going to use yet more powerful antibiotics which may cause yet more truculent complications?

\section{REFERENCE}

1. Chiba N, Rao BV, Rademaker JW, Hunt RH. Meta-analysis of the efficacy of antibiotic therapy in eradicating Helicobacter pylori. Am J Gastroenterol 1992;87:1716-27.

\section{Rebuttal: EOIN A LALOR}

T O BEGIN WITH, HELICOBACTER-NEGATIVE DUODENAL ulcers are thought by some researchers to predict gastrinoma or Crohn's disease, and it is suggested that the presence of these ulcers should prompt a search for an endocrine tumour as well as a search for NSAIDs use and cigarette smoking. I think you will find more helicobacter-negative ulcers if you don't use the more sensitive tests; you need a pathologist or a microbiologist devoted to finding these organisms. Local anesthetic spray, and other transport methods affect the positive culture rate. The rapid urease test is really not a gold standard, and at our institution we get adequate information from the $\mathrm{H} \& \mathrm{E}$ stain, but culture may be required, especially in cases where initial eradication therapy has failed. The NSAID-induced gastric ulcer which Dr Hershfield mentioned was investigated by Dr D Graham recently. His conclusion was that there was no difference in the rate of NSAID-induced ulceration between helicobacterpositive and helicobacter-negative patients (1). This finding remains controversial.

As to current treatment, while the rate of ulcer operations has certainly declined in the recent past, information on peptic ulcer morbidity and mortality rates indicate that equal numbers of patients, especially in older age groups, are either going to surgery for complications or dying from peptic ulcer disease, and $\mathrm{H}_{2}$-blockers have not had any impact on this mortality rate.

The side effects of triple therapy are, indeed, significant, and you need to look at the drop-out rate in these trials and analyze the trials on an intent-to-treat basis. I think some patients will not be able to take triple therapy, especially if they have an acute ulcer. Therefore, the general consensus is now to heal the ulcer and then to eradicate the helicobacter. The inclusion of metronidazole in the treatment regimen might reduce the risk of pseudomembranous colitis, although clearly this would not be completely preventative. I think the suggestion that a treatment regimen might consist of more than three drugs is an exaggeration. Bismuth is one of the antibiotics; it is bactericidal for helicobacter in vivo, possibly via the mechanism of inactivating urease. We are, therefore, talking about bismuth plus two antibiotics. In the future, treatment may consist of two antibiotics plus some other agent. 
As for the long term study, there is one four-year follow-up trial by Borody and colleagues (2) (who had some drop-out, but his follow-up was really quite good); their data support long term eradication and a lack of reinfection. I believe that if you wait one month after eradication therapy and then biopsy aggressively in the antrum (two or three times), the absence of the organism and of chronic gastritis is good proof of eradication. Even if you are reinfected (which appears to be infrequent), the chances are that you may be reinfected with a different organism, perhaps one of the 'nonpathogenic' species. We currently believe there to be several different strains which have different cytotoxins and different enzymes. This may explain the fact that large numbers of patients with helicobacter never develop duodenal ulcer disease.

\section{REFERENCES}

1. Graham DY, Lidsky MD, Coe AM, et al. Long term nonsteroidal anti-inflammatory drug use and Helicobacter pylori infection. Gastroenterology 1991;100:1653-7.

2. Borody TJ, Cole P, Noonan S, et al. Recurrence of duodenal ulcer and Campylobacter pylori infection after eradication. Med J Aust 1989;151:431-5.

\section{Final Rebuttal: NOEL B HERSHFIELD}

I N THE FIRST PLACE, AS FAR AS REINFECTIONS RATES GO, 1 recent studies have shown that there is a familial incidence of this disorder. If you have helicobacter, your wife or your children probably also have it, generally unbeknownst to you - so this would be one way patients would be reinfected. I think a second important fact is that gastroenterologists are at risk. Studies show this organism to be more common in gastroenterologists than not - obviously helicobacter is being transmitted from patient to gastroenterologist, and quite likely to nurses as well.

Also, I don't think anybody really knows what the recurrence rate of duodenal ulcer disease actually is because patients come to see their physicians for specific symptoms and the physician finds out by investigation that these patients have duodenal ulcer disease. Many patients who have ulcers are asymptomatic. It is difficult to compare the effects of treatment with $\mathrm{H}_{2}$ inhibitors, placebo or antibiotics because we don't really know the true recurrence rate of duodenal ulcer.

Finally, about the money that might be saved - the US $\$ 60$ billion in the United States is only a valid figure if we can prove that this treatment works. I don't know what the exact cost of three antibiotics and bismuth is, and thus I'm not quite sure what the cost would be for one month. I do think that the cost of $\mathrm{H}_{2}$ inhibitors and omeprazole will come down in the future, and standard treatment will be much less expensive. Therefore, I still feel that at the present time (1991) we should not use multiple antibiotic or drug therapies, of which there are far too many being prescribed anyway in this society. We should stick with what we've got at the moment.

ACKNOWLEDGEMENT: This debate was supported by an educational grant from Eli Lilly Canada Inc. 


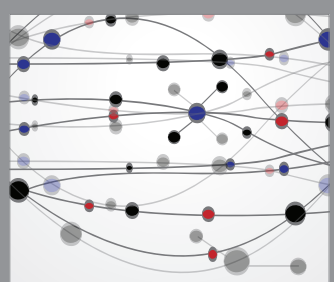

The Scientific World Journal
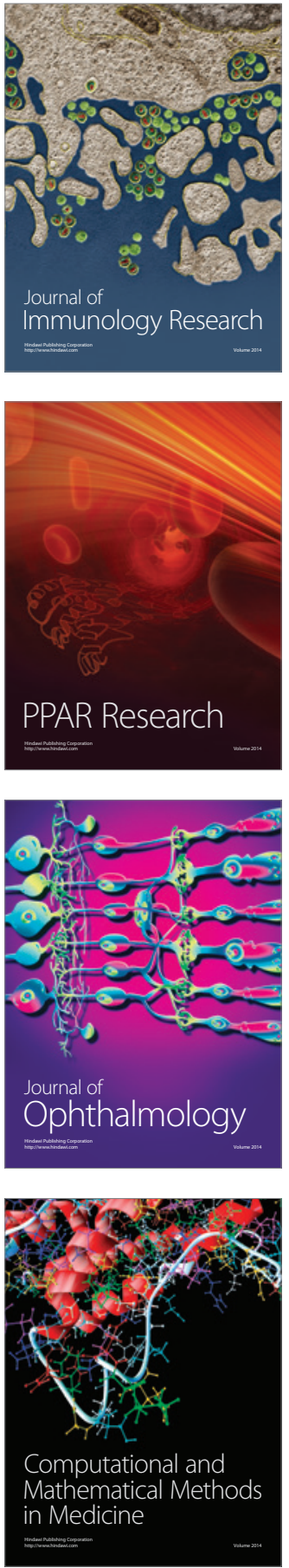

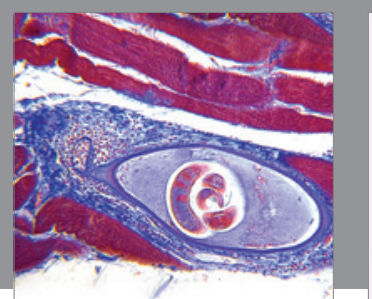

Gastroenterology Research and Practice

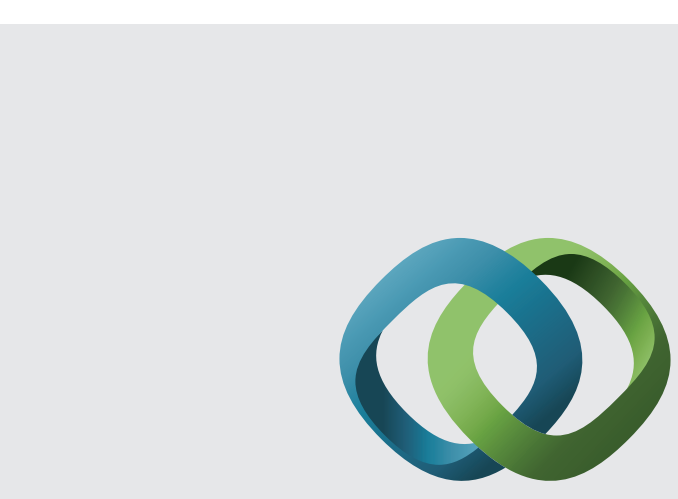

\section{Hindawi}

Submit your manuscripts at

http://www.hindawi.com
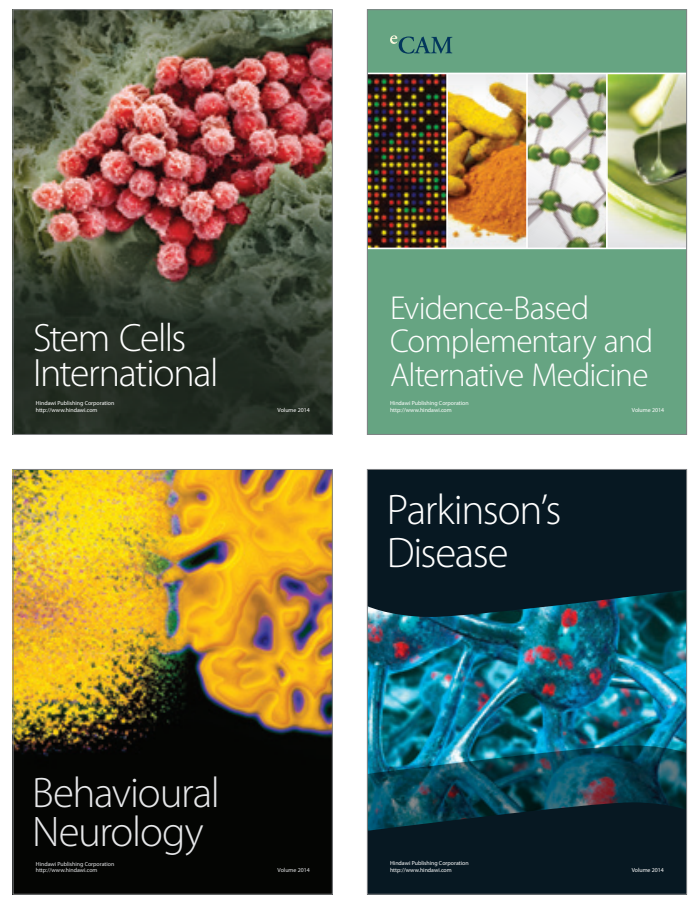
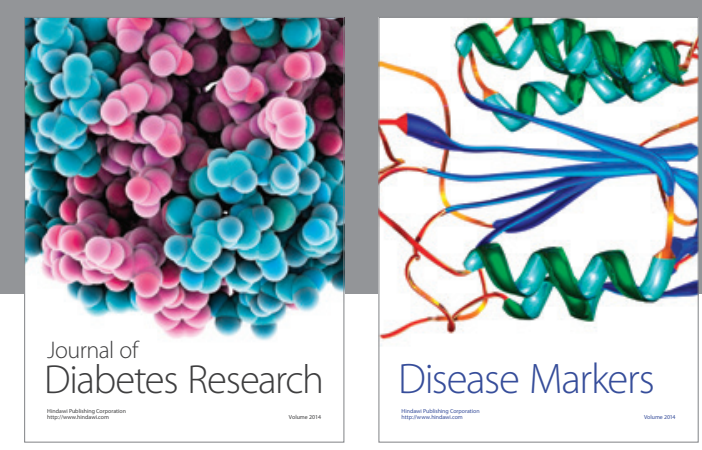

Disease Markers
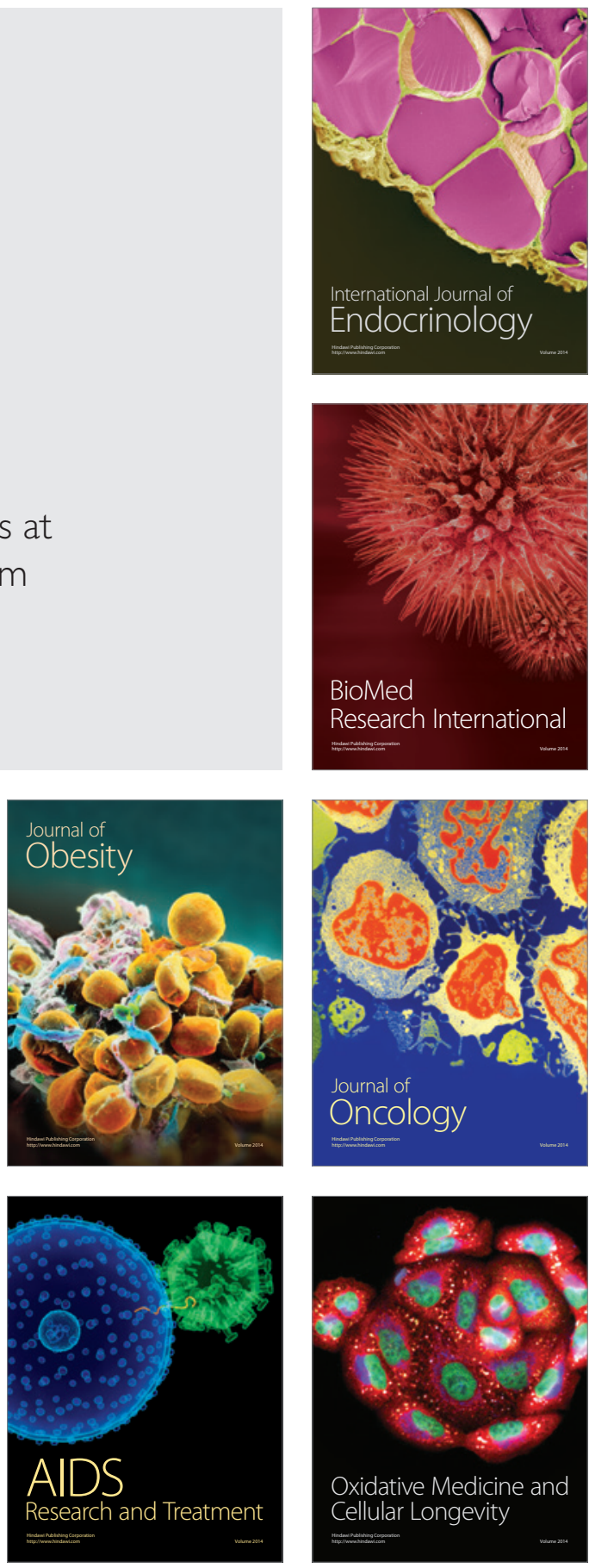